\title{
Os trabalhadores negros em $3 \times 4$ : fotografia, história do trabalho e pós-abolição. Pelotas-RS, 1933-1944
}

The black workers in 3x4: photography, work history and post-abolition. Pelotas-RS, 1933-1944

\section{Aristeu Elisandro Machado Lopes*}

Resumo: A proposta deste artigo é analisar um conjunto de informações e as fotografias $3 \times 4$ dos trabalhadores negros que solicitaram carteira profissional, no município de Pelotas/RS, entre os anos de 1933 e 1944. Como a cidade se caracterizou, no século XIX, pela ascensão econômica advinda da exploração da mão de obra escravizada, a proposta se desenvolverá, também, abordando questões sobre a presença da população negra a partir dos dados demográficos disponíveis. O objetivo principal, todavia, será a análise das informações do acervo da Delegacia Regional do Trabalho do Rio Grande do Sul, constituído por uma ficha que registrava os dados do trabalhador, as impressões digitais dos dedos das mãos e uma fotografia no formato $3 \times 4$. A fotografia dos trabalhadores negros é considerada como um importante registro visual da população negra da cidade, uma vez que pouco ou quase nada foi preservado sobre a história desses homens e mulheres, nas primeiras décadas do século XX.

Palavras-chave: carteira profissional; pós-abolição; Pelotas.

Abstract: The purpose of this article is to analyze a set of information and the $3 \times 4$ photographs of Black workers who applied for the professional portfolio in the city of Pelotas/RS, between 1933 and 1944. Considering that the city was characterized in the nineteenth century by the economic rise from the exploitation of slave labor, the proposal will also develop, addressing questions about the presence of the black population based on available demographic data. However, the main objective will be the analysis of the information from the acquis of the Regional Labor Office of the state of Rio Grande do Sul, consisting of a form that recorded the worker data, fingerprints, and a $3 \times 4$ photograph. The photography of black workers is considered an important visual record of the black population of the city, since practically nothing was preserved about the history of these men and women in the early decades of the twentieth century.

Keywords: working papers; post-abolition; Pelotas.

* Doutor em História pela UFRGS. Professor Associado do Departamento e do Programa de Pós-Graduação em História da UFPel. Pesquisador do Programa Pesquisador Gaúcho da FAPERGS. E-mail: aristeuufpel@yahoo.com.br. ORCID: https://orcid.org/0000-0003-0897-5331. 


\section{Considerações iniciais - ou considerações sobre um encontro}

O ano era 2000, o ano do primeiro encontro, do primeiro semestre, da primeira aula e do começo de uma relação que perduraria por muitos outros anos. Aquele foi o ano do início da minha trajetória acadêmica, como calouro, do curso de Licenciatura em História da Universidade Federal de Pelotas. No primeiro semestre, o primeiro encontro com a professora Beatriz Ana Loner, na disciplina Introdução aos Estudos Históricos, minha primeira impressão - e certamente de muitos dos meus colegas foi de uma professora exigente, mas totalmente compromissada com o ensinar a história, com a preparação dos novos professores e pesquisadores que formaria, em explicar que a história é muito mais do que meras datas, nomes e eventos. $\mathrm{Na}$ sequência do curso, trabalhamos em um projeto de extensão na Biblioteca Pública Pelotense, na organização de um acervo de livros recém-chegado na instituição, e no projeto de pesquisa "Trabalhadores e Literatura em Pelotas no século XIX", meu primeiro contato com os preciosos periódicos de Pelotas.

Nos dois últimos semestres do curso, me tornei seu bolsista de Iniciação Científica, dando continuidade ao projeto dos trabalhadores envolvidos com a literatura. Beatriz teve a sensibilidade de perceber que alguns trabalhadores de Pelotas, que atuavam nos sindicatos e nas associações operárias, tinham seus ofícios, mas nem por isso deixavam de contribuir com produções literárias destinadas aos jornais da cidade. Assim ela se referiu a eles:

\footnotetext{
Homens que, tendo outras profissões que Ihe garantiam o sustento - variadas profissões, a bem da verdade, tais como redatores, professores, advogados, músicos, mas também artesãos dos mais variados ofícios -, dedicavam pequena parte de seu tempo para a arte literária, deixando apenas alguns poemas, um ou outro conto e talvez meia dúzia de crônicas. ${ }^{1}$
}

O projeto, portanto, permitia abordar outros temas, para além dos universos político e sindical nos quais eles estavam envolvidos, e entrava na seara da produção literária que, embora pequena, era considerável.

O ano de 2004 foi o fim de um ciclo, com a conclusão do curso e a formatura - minha turma escolheu Beatriz como paraninfa e patrona, talvez algo único na história do curso - mas a amizade e o contato não findaram. O reencontro aconteceu em 2010. Depois da conclusão do doutorado e da aprovação em concurso público, retornei à UFPel como professor do Departamento de História; o ex-aluno agora se 
tornava colega da professora tão admirada! Deste reencontro e da minha vinculação ao Núcleo de Documentação Histórica da UFPel, fundado por Beatriz em 1990, recebi a incumbência de cuidar do acervo da Delegacia Regional do Trabalho do Rio Grande do Sul, em 2011, logo após a sua aposentadoria.

O acervo da DRT/RS é formado por 627.000 fichas de qualificação profissional, que são formulários com os dados pessoais e profissionais dos solicitantes de carteira profissional, preenchidas entre os anos de 1933 e $1968 .{ }^{2}$ Esses documentos são importantes para compreender as relações entre o governo iniciado após 1930 e os trabalhadores; como aponta Angela de Castro Gomes, a carteira profissional demonstrava o tipo de relação, entre o governo e os trabalhadores, que se desejava construir naquele momento histórico. ${ }^{3} \mathrm{~A}$ iniciativa de Beatriz Loner em receber, no ano de 2001, e salvaguardar no NDH/ UFPel esse acervo, que estava aos cuidados do Núcleo de Pesquisa em História da Universidade Federal do Rio Grande do Sul, ${ }^{4}$ é louvável, pois se trata de um conjunto único desse tipo de documento e que permite compreender parte da história dos trabalhadores do Rio Grande do Sul, evidenciando homens e mulheres comuns como os trabalhadores negros de Pelotas.

O objetivo do artigo, além de contribuir com os estudos sobre os mundos do trabalho e o período pós-abolição em Pelotas, o que vai ao encontro das pesquisas realizadas por Beatriz Loner, é apresentar as informações registradas nas fichas de qualificação profissional dos trabalhadores negros nascidos em Pelotas e que estavam trabalhando na cidade no momento da solicitação da carteira. A proposta deste artigo também tem por objetivo dar visibilidade para o trabalhador negro e para a trabalhadora negra contribuindo para a discussão proposta por Álvaro Nascimento. ${ }^{5}$ Para o autor, a invisibilidade dos negros na historiografia sobre trabalhadores pobres e o movimento operário no Brasil se caracteriza por uma ausência, a qual é "ainda maior nas pesquisas voltadas para os séculos $\mathrm{XX}$ e XXI,

A carteira profissional foi estabelecida a partir do Decreto-Lei n. ${ }^{\circ} 21.175$, de 21 de março de 1932 , que previa, em seu $21^{\circ}$ artigo: "Após doze meses de vigência do presente decreto, o Ministério do Trabalho, Indústria e Comércio só tomará conhecimento das queixas e reclamações dos empregados que possuírem carteiras profissionais". BRASIL. Decreto n. $^{\circ} 21.175$, de 21 de março de 1932. Institui a carteira profissional. Disponível em: http://www2.camara.leg.br/legin/fed/ decret/1930-1939/decreto-21175-21-marco-1932-526745-publicacaooriginal-1-pe.html. Acesso em: 21 out. 2017.

3 GOMES, Angela de Castro. A invenção do trabalhismo. Rio de Janeiro: Editora FGV, 2005. p. 223.

4 LONER, Beatriz Ana. O acervo sobre trabalho do Núcleo de Documentação Histórica da UFPel. In: SCHMIDT, Benito Bisso (Org). Trabalho, justiça e direitos no Brasil. Pesquisa histórica e preservação das fontes. São Leopoldo: Oikos, 2010. p. 19.

5 NASCIMENTO, Álvaro Pereira. Trabalhadores negros e o "paradigma da ausência": contribuições à História Social do Trabalho no Brasil. Estudos Históricos, Rio de Janeiro, v. 29, n. 59, p. 607626, 2016. 
quando a cor dos trabalhadores é frequentemente invisibilizada". ${ }^{6} \mathrm{~A}$ pesquisa que será apresentada neste texto abordará um grupo de trabalhadores negros, entre os anos de 1933 e 1944, portanto, dando visibilidade para uma parcela de suas trajetórias profissionais.

Serão analisados os dados das fichas que estão incluídos em um banco de dados que contém as informações das fichas a partir de 1933 e, neste momento, recebe informações daquelas solicitadas no ano de $1944 .{ }^{7} \mathrm{O}$ banco de dados é outra iniciativa importante de Beatriz Loner, pois foi ela, através do concurso "Memória do Trabalho", conduzido pelo CPDOC-FGV e patrocinado pela Petrobras, que captou os recursos necessários para o seu desenvolvimento.

O primeiro dado que norteará a pesquisa é o registro da cor do trabalhador, conforme preenchido na ficha, uma vez que, a partir dele, será possível apresentar as quantidades das solicitações divididas pelas cores registradas. Na sequência, e em relação somente aos trabalhadores negros, pretende-se avaliar as suas profissões, sexo, escolaridade, estado civil, entre outros dados. A análise também se direcionará à fotografia $3 \times 4$ do trabalhador que era afixada no verso dos documentos de solicitação da carteira. As fotografias são entendidas como importantes registros visuais dos trabalhadores negros, uma vez que pouco ou quase nada foi preservado sobre a história visual desses homens e mulheres comuns, nas primeiras décadas do século $X X .^{8}$

\section{A presença dos trabalhadores negros em Pelotas}

Auguste Saint-Hilaire, em sua Viagem ao Rio Grande do Sul, realizada em 1820 , registrou, quando de sua passagem por Pelotas, a seguinte constatação sobre as charqueadas: "Embora há vários meses não se abatam animais nas charqueadas, sente-se, nos arredores, um cheiro bastante forte de matadouro e, por isso, pode-se fazer ideia do quanto deve ser desagradável esse odor nos tempos de matança". 9 Já o Conde d’Eu, ao visitar a cidade em 1865, destacava que “o rápido desenvolvimento

6 Ibidem, p. 609. No entanto, o autor destaca trabalhos realizados por historiadores da escravidão e da pós-abolição que investigaram mulheres e homens negros contribuindo para a visibilidade dos trabalhadores negros. Ibidem, p. 611-612.

7 Atualmente o banco de dados possui 48.250 fichas inseridas. Com ele é possível selecionar e cruzar as informações e estabelecer perfis de trabalhadores de acordo com as intenções da pesquisa.

8 Mariana Couto Gonçalves apresenta em sua tese de doutorado um diagnóstico sobre a produção de fotografias nas primeiras décadas do século $X X$, em Pelotas, nas revistas, nos jornais e nos almanaques publicados nesse período. A autora ressalta a quase inexistência de pessoas negras nessa produção. GONÇALVES, Mariana Couto. "Andei, sempre tendo o que ver e ainda não fora visto": a modernização urbana pelotense a partir de crônicas e fotografias (1912-1930). 2017. Tese (Doutorado em História) - Universidade do Vale do Rio dos Sinos, São Leopoldo, 2017.

9 SAINT-HILAIRE, Auguste. Viagem ao Rio Grande do Sul. Brasília: Senado Federal, 2002. p. 122. 
de Pelotas é um fato notável, que não encontra análogo na província e que pressagia a esta cidade um futuro considerável". ${ }^{10}$

Duas narrativas distintas, dois pontos de vista sobre Pelotas. Uma cidade com contrastes: por um lado, havia o predomínio da utilização da mão de obra escravizada nas charqueadas, principal produto que movimentava a economia pelotense; por outro, em consequência desse primeiro aspecto, o surgimento de uma elite que se caracterizou por sua cultura e opulência. ${ }^{11} \mathrm{~A}$ produção do charque promoveu grande visibilidade para a cidade, como destaca Jonas Vargas: "Em poucas décadas, Pelotas ficaria conhecida por todos os grandes comerciantes marítimos daAmérica portuguesa, pois havia se tornado a principal produtora de carne-seca do Império luso-brasileiro". ${ }^{12}$ No entanto, no final do século XIX, a situação econômica passava por uma fase de deterioração da indústria da carne provocada, principalmente, pela falta de uma modernização nas atividades econômicas. Concomitante, havia uma diversificação do mercado de trabalho, sobretudo em relação ao comércio e às fábricas. A situação não sofreu grandes alterações nas primeiras décadas do século XX:

\begin{abstract}
O levantamento de 1911, efetuado pela Seção de Estatística do município de Pelotas, apresentou um quadro industrial da cidade ainda não muito diferente do anterior, com a maior parte dos estabelecimentos concentrando-se nos ramos de alimentação, olaria e produtos derivados da pecuária, como charqueadas, curtumes, calçados, malas, cola, velas, sabões, graxas e perfumaria, além de escovas e vassouras. Fora estas, existiam apenas algumas de roupas e tecidos; uma de vidros; seis de móveis de madeira e vime; um de instrumentos musicais; dois de coroas de flores; três de fogos de artifício; destacando-se seis de fabricação de carros e dois estaleiros navais. ${ }^{13}$
\end{abstract}

No que se refere às charqueadas, como verificado pelo levantamento de 1911, citado por Beatriz Loner, elas permaneceram nas décadas do novo século, mas a sua matéria-prima, a carne bovina, estava em um novo estágio de produção, a qual ainda não era realizada em Pelotas. Em outras palavras, o processo de transformação da carne verde em carne congelada ou frigorificada foi tardio se comparado, por exemplo, com outras regiões do estado, do Brasil e até mesmo com a indústria da carne platina. ${ }^{14}$ Apesar de resistir, ainda na década de 1930, a

10 CONDE D’EU. Viagem militar ao Rio Grande do Sul. São Paulo: Companhia Editora Nacional, 1936. p. 213.

11 MAGALHÃES, Mário Osório. Opulência e cultura na Província de São Pedro do Rio Grande do Sul. Um estudo sobre a história de Pelotas (1860-1890). Pelotas: Editora da Universidade/UFPel, Livraria Mundial, 1993.

12 VARGAS, Jonas Moreira. Os barões do charque e suas fortunas. Um estudo sobre as elites regionais brasileiras a partir de uma análise dos charqueadores de Pelotas (Rio Grande do Sul, século XIX). São Leopoldo: Oikos, 2016. p. 29.

13 LONER, Beatriz Ana. Construção de classe. Operários de Pelotas e Rio Grande. 2. ed. Pelotas: Editora da UFPel, 2016. p. 41.

14 Sobre a instalação dos frigoríficos na América do Sul, ver: MICHELON, Francisca Ferreira. 
atividade charqueadora não era mais a mesma dos tempos áureos da produção do século XIX.

Conforme os dados do censo de 1853, Pelotas contava com 38 charqueadas nesse período. ${ }^{15}$ De acordo com Beatriz Loner: "De um total de 34 charqueadas existentes em 1878 na cidade, elas reduziram-se a apenas 21 às vésperas da Abolição e a 18, dois anos depois". ${ }^{16}$ Ainda sobre as charqueadas em 1890, conforme os dados do censo daquele ano, elas eram "responsáveis pela industrialização de 270.600 reses na safra. Dessas, 16 industrializaram mais de 10.000 bois cada uma, na safra 89-90, o que permite considerá-las como de grande porte". ${ }^{17}$ No começo do século XX, conforme o Almanach de Pelotas, as charqueadas totalizavam cinco estabelecimentos em $1918 .{ }^{18}$ Já nos dados da DRT/RS, foram localizadas apenas oito fichas de trabalhadores que declararam o local de trabalho como charqueada em Pelotas, todos na Charqueada Viúva Pedro Osório e Companhia.

A população negra de Pelotas, vinculada, sobretudo, ao trabalho nas charqueadas no século $\mathrm{XIX} e$, nas primeiras décadas do século $\mathrm{XX}$, aos mais diversificados ofícios, constou sempre, e até a atualidade, na demografia do município. Um exemplo está nos dados demográficos publicados pela Revista do $1^{\circ}$ Centenário de Pelotas, publicada pelo escritor João Simões Lopes Neto, em 1912. Conforme a publicação, em 1814, ainda como Freguesia, foram contabilizados em Pelotas 2.419 habitantes. Entre eles, os escravizados somavam 1.225 pessoas. ${ }^{19}$

Já Margaret Bakos aponta que em 1859 a população escravizada em Pelotas era constituída por 4.788 pessoas. ${ }^{20}$ Os dados do censo de 1872 apontam para uma população total de 14.762 pessoas, dividida entre 12.376 livres e 2.386 escravizados. Entre os livres, havia 9.021 brancos, 1.848 pretos, 1.347 pardos e 160 caboclos. Entre os escravizados, 1.259 homens e 1.127 mulheres. ${ }^{21}$ Nos anos 1880 , as estatísticas sobre os escravizados na cidade variavam constantemente. No ano

Sociedade Anônima Frigorífico Anglo de Pelotas: o trabalho do passado nas fotografias do presente. Pelotas: Editora da UFPel, 2012.

15 FUNDAÇÃO DE ECONOMIA E ESTATÍSTICA. De província de São Pedro a Estado do Rio Grande do Sul. Censos do RS: 1803-1950. Porto Alegre: FEE-RS, 1981. p. 63.

16 LONER, Beatriz Ana. Negros: organização e luta em Pelotas. História em Revista, Pelotas, v. 5, p. 1, dez. 1999.

17 Idem, op. cit., 2016, p. 40.

18 ABREU, Gonçalo. A indústria do charque em Pelotas. Almanach de Pelotas, Pelotas, ano VIII, 1920. p. 294.

19 LOPES NETO, João Simões. Revista do $1^{\circ}$ Centenário de Pelotas, Pelotas, n. 2, p. 5, 25 nov. 1911.

20 BAKOS, Margaret. RS: escravismo e abolição. Porto Alegre: Mercado Aberto: 1982. p. 22.

21 INSTITUTO BRASILEIRO DE GEOGRAFIA E ESTATÍSTICA. Recenseamento do Brasil em 1872. Rio Grande do Sul. Rio de Janeiro: G. Leuzinger, 1874[?]. p. 130. Disponível em: https://biblioteca. ibge.gov.br/biblioteca-catalogo.html?id=225477\&view=detalhes. Acesso em: 3 mar. 2018. 
de 1884 , o número de escravizados atingiu a quantidade de 6.526 pessoas; no ano seguinte, diminuiu para 2.831, e nas vésperas da Abolição, em 1887, contava com 338 escravizados. ${ }^{22}$

Conforme Beatriz Loner, a diminuição dos escravizados deve-se à política de transformá-los em contratados. ${ }^{23}$ Tal política não significou que a tortura e as formas de sujeição tenham sido igualmente abolidas. Os contratados ainda estavam suscetíveis aos castigos impostos por seus senhores, como exemplifica o assassinato da contratada Pórcia, em 1884, morta com requintes de crueldade, amplamente noticiado na imprensa da época. ${ }^{24}$

Os dados demográficos do Rio Grande do Sul, nas primeiras décadas do século XX, apresentam informações sobre as cores dos habitantes. No censo de 1940, a divisão por cor foi apurada, e no Rio Grande do Sul obteve os seguintes dados: 2.944.204 brancos, 220.659 pretos, 943 amarelos, ${ }^{25} 153.376$ pardos e 1.607 sem declaração de cor. ${ }^{26}$ Já as informações específicas sobre Pelotas apontaram para uma população formada por 88.918 brancos, 9.620 pretos, 15 amarelos, 5.961 pardos e 39 com cor não declarada. ${ }^{27}$ Tais dados demonstram a permanência de uma parcela da população preta e parda no estado, embora predominasse a população branca. Situação semelhante é verificada nos dados sobre Pelotas, com um total de brancos superior em relação àqueles com outras cores.

O resultado do número de brancos se deve, em grande parte, às políticas de imigração que incentivavam a vinda para o estado de uma mão de obra branca e europeia, a qual era preferida pelas empresas da época. ${ }^{28}$ Essa condição também foi verificada em Pelotas. Beatriz Loner destaca que havia trabalhadores negros em praticamente todas as atividades manuais, como trabalhadores especializados e operários artesãos, os quais "sofriam a concorrência de artesãos e trabalhadores brancos, principalmente imigrantes, portugueses ou de outras nacionalidades, situação que deve ter-se acentuado ainda mais com o fluxo imigratório dos primeiros

22 BAKOS, Loc. cit.

23 LONER, op. cit., 1999, p. 1.

24 GUEDES, Geza Carús. Criminalidade feminina: mulheres negras e os homicídios em Pelotas (1880-1890). 2014. Dissertação (Mestrado em História) - Instituto de Ciências Humanas, Universidade Federal de Pelotas, Pelotas, 2014. p. 127-141.

25 Sobre o sistema de cores adotado pelo IBGE, no censo realizado em 1940, ver: SPERANZA, Clarice Gontarski. Branco, preto, pardo, moreno ou escuro? Classificações raciais nas carteiras dos trabalhadores gaúchos (1933-1945). Tempos Históricos, v. 21, p. 100-124, 2017.

26 FUNDAÇÃO DE ECONOMIA E ESTATÍSTICA. De província de São Pedro a Estado do Rio Grande do Sul. Censos do RS: 1803-1950. Porto Alegre: FEE-RS, 1981. p. 190.

27 INSTITUTO BRASILEIRO DE GEOGRAFIA E ESTATÍSTICA. Recenseamento Geral do Brasil ( $1^{\circ}$ de Setembro de 1940). Série Regional. Parte XX - Rio Grande do Sul. Tomo I. Rio de Janeiro: Serviço Gráfico do Instituto Brasileiro de Geografia e Estatística, 1950. p. 53. Disponível em: https://biblioteca.ibge.gov.br/visualizacao/monografias/GEBIS\%20-\%20RJ/CD1940/Censo\%20 Demografico\%201940_pt_XX_t1_RS.pdf. Acesso em: 3 abr. 2019.

28 PESAVENTO, Sandra Jatahy. Emergência dos subalternos. Porto Alegre: UFRGS, 1989. p. 71. 
anos da República". ${ }^{29}$ Tanto no que se refere ao estado do Rio Grande do Sul, como especificamente sobre Pelotas, a população negra permaneceu presente nos mundos do trabalho. As condições sociais e econômicas, contudo, não proporcionaram uma transformação nas profissões desempenhadas pelos trabalhadores negros das primeiras décadas do século $X X$, mas sim, certa permanência das atividades nas quais estavam envolvidos os trabalhadores do século XIX:

Com a Abolição e a República, muitos deles permaneceram na região, desenvolvendo as mesmas atividades que anteriormente nas charqueadas e também empregando-se em fábricas, na construção civil e nos trabalhos do porto. Praticamente eles eram encontrados em todo o tipo de trabalho manual, especialmente naqueles mais árduos e estafantes. Diferentemente de seus companheiros brancos, os trabalhadores negros enfrentavam obstáculos maiores à ascensão social, e assim, ao longo do tempo, estiveram presentes em todas as profissões, incluindo os operários de fábricas, chapeleiros, construtores civis, empregados em indústrias de conservas e alimentação, tipografias etc. ${ }^{30}$

Nos dados das fichas de qualificação profissional são encontradas muitas informações sobre os trabalhadores negros pelotenses que vão ao encontro do que é colocado por Beatriz Loner. O tópico seguinte apresentará esses dados, os quais se aproximam das características evidenciadas na citação, no que se refere ao tipo de trabalho manual e indicam os possíveis obstáculos à ascensão social.

\section{Os trabalhadores negros de Pelotas nas fichas da DRT/RS}

Os dados conservados no acervo da Delegacia Regional do Trabalho do Rio Grande do Sul apontam que as fichas dos trabalhadores que registraram sua cor como preto ou preta constitui uma parcela menor de trabalhadores do que aquela formada pelos que tiveram a cor branca informada em suas fichas. ${ }^{31}$ Até o momento, foram localizadas 1.573 solicitações de carteira profissional de trabalhadores nascidos em Pelotas. No que se refere ao campo "cor", 1.278 fichas com identificação como branca, 151 como parda, 99 como preta, ${ }^{32} 29$ como morena, 12 como mista e uma como clara; além de três fichas nas quais não consta a cor do trabalhador.

\section{LONER, op. cit., 1999, p. 3.}

Loc. cit.

31 Importante destacar que as informações constantes no acervo da DRT/RS não se referem ao universo dos trabalhadores de Pelotas, ou seja, apresenta os dados somente daqueles que solicitaram carteira profissional e que tiveram suas fichas conservadas. $O$ total de trabalhadores, incluindo, provavelmente, os negros, é muito maior.

32 Entre os 99 trabalhadores com fichas com o registro da cor como preta, 60 solicitaram entre 1939 e 1944. 
É difícil apontar se as cores anotadas nas fichas foram declaradas ou não pelo solicitante, uma vez que esse campo poderia ser preenchido pelo funcionário da DRT/RS, levando em consideração apenas a sua percepção de qual cor era a mais apropriada sem ponderar a opinião do trabalhador. No entanto, uma cor como "claro" - além de outras denominações que aparecem nas fichas de trabalhadores de outras cidades como: "crespo", "castanho", "trigueira", "indiática", "louro", "escura" - podem ser um indício de uma auto-declaração do trabalhador. Ainda, a falta de critérios sobre as definições das cores, que somente foram estabelecidos a partir do censo de 1940 com três cores oficiais: "branca" "preta" e "amarela", mas que não foi seguido pela DRT/RS, possibilitou o surgimento de denominações variadas.

A partir do número de solicitações de carteiras de trabalhadores nascidos em Pelotas, foi realizado outro filtro, no banco de dados, localizando entre eles aqueles que estavam trabalhando na cidade, no momento da solicitação da carteira. Essa seleção apresenta o total de 835 trabalhadores, distribuídos nas seguintes cores: 656 branca, 98 parda, 15 morena, 60 preta, cinco mista e um que se declarou como claro.

Os dados acima demonstram a predominância dos trabalhadores brancos em ambos os grupos, ou seja, tanto entre aquele de trabalhadores nascidos em Pelotas, como naquele dos nascidos e que estavam trabalhando na cidade no momento em que solicitaram suas carteiras. O número de solicitações é pequeno quando comparado com os resultados do censo de 1940 (9.620 habitantes com registro de cor preta), que é o mais próximo aos dados da DRT/RS. Onde estavam os demais trabalhadores e trabalhadoras, com cor preta, de Pelotas? É possível apontar uma resposta baseada nas afirmações de Beatriz Loner, em citação anterior, quando explica que os negros e as negras pelotenses continuaram desenvolvendo as mesmas atividades remanescentes do século XIX, nas charqueadas que perduraram, nas fábricas que surgiram, na construção civil, no porto da cidade e em um número variado de trabalhos autônomos. A hipótese que corrobora a construção dessa resposta está no entendimento de que, na maioria dessas ocupações, a carteira profissional nem sempre era considerada como um documento importante e uma parte significativa desses trabalhadores - muitos descendentes de trabalhadores escravizados ou nascidos livres na Pelotas escravocrata do século XIX - continuava à margem do trabalho considerado regularizado, com carteira emitida e assinada pelo empregador.

A análise das ocupações declaradas pelos 60 solicitantes de cor preta coopera com a hipótese desenvolvida. O quadro abaixo apresenta as profissões: 


\section{Quadro 1}

Solicitações de carteira em Pelotas por trabalhadores negros, por profissão.

\begin{tabular}{|l|c|}
\hline Profissões & Número de trabalhadores \\
\hline Sapateiro & 8 \\
\hline Curtumeiro & 6 \\
\hline Servente pedreiro & 5 \\
\hline Operário & 5 \\
\hline Carpinteiro & 3 \\
\hline Pedreiro & 3 \\
\hline Magarefe & 3 \\
\hline Servente & 2 \\
\hline Oleiro & 2 \\
\hline Costureiro/costureira & 2 \\
\hline $\begin{array}{l}\text { Mosaiqueiro/ Instalador de redes/ Fundidor de } \\
\text { granilite/ Ensacador/ Fiador/ Estivador/ Marceneiro/ }\end{array}$ & 1 \\
$\begin{array}{l}\text { Foguista/ Alfaiate/ Pintor/ Carroceiro /Mecânico/ } \\
\text { Carregador/ Lustrador/ Ajudante de mecânico/ } \\
\text { Ajudante de ferreiro/Trabalhador braçal/ Lavadora } \\
\text { de garrafas/ Ajudante de pedreiro/Trabalhadora em } \\
\text { barraca/Ajudante de funileiro }\end{array}$ & \\
\hline
\end{tabular}

Fonte: Acervo da Delegacia Regional do Trabalho do Rio Grande do Sul/Núcleo de Documentação Histórica da UFPel.

Entre as duas ocupações com maior demanda estão sapateiro, com oito trabalhadores, e curtumeiro, com seis trabalhadores. Ambas profissões estão relacionadas ao manuseio do couro: a primeira poderia ser a confecção de sapatos, sandálias e chinelos ou o conserto desses itens, enquanto a segunda manuseava uma matéria-prima, ou seja, o couro retirado de animais abatidos. As fábricas de calçados e os curtumes estavam instalados na cidade desde o século XIX e, em 1925, por exemplo, havia 22 fábricas de calçados e 33 curtumes. ${ }^{33}$

Já entre os magarefes ${ }^{34}$ havia apenas três trabalhadores, enquanto como oleiros figuram apenas dois trabalhadores. Essas são profissões que certamente havia muitos outros trabalhadores, já que a história da cidade está relacionada com os ofícios destinados ao trabalho de abates de animais e também às olarias. Essas duas profissões podem ser apontadas, mais diretamente, como semelhantes àquelas

LONER, op. cit., 2016, p. 335-337.

34 Magarefe é o profissional especializado no abate e na separação das partes do animal, sinônimo para açougueiro, carniceiro ou carneador. FERREIRA, Aurélio. Novo Dicionário Aurélio da Língua Portuguesa. 3. ed. Curitiba: Positivo, 2004. p. 1.248. 
desempenhadas pelos trabalhadores escravizados no século XIX pelotense. Ester Gutierrez explica que o trabalho nas charqueadas envolvia não apenas a fabricação do charque, mas também uma produção dos produtos derivados do animal, o que envolvia profissões não especializadas e especializadas: "o trabalho não especializado na fabricação de carne salgada, couro, sebo e graxas ocupava muitos cativos"; já aqueles considerados especializados eram os que "se dedicavam, quase exclusivamente e de forma direta, à produção e ao transporte da carne salgada e dos seus subprodutos, exercendo as funções de carneador, salgador, graxeiro, descarnador, chimango, servente e marinheiro". ${ }^{35}$

Contudo, é importante considerar que o produto principal das charqueadas era a carne salgada, o que pode explicar a ausência de uma mão de obra especializada no manuseio do couro. Essa explicação, sobre as profissões nas charqueadas, é relevante, uma vez que, comparando com aquelas com maior número de trabalhadores de Pelotas, se percebe certa continuidade do trabalhador negro em profissões relacionadas ao trabalho com o abate de animais e, especificamente, com a manufatura do couro, ou seja: sapateiros, curtumeiros e magarefes. Por outro lado, ao observar o quadro com as profissões, se nota que há uma diversificação das profissões ocupadas pelos trabalhadores negros de Pelotas que solicitaram suas carteiras profissionais.

Um segundo grupo estava relacionado ao ramo da construção com seis serventes de pedreiro, três pedreiros, um pintor e um ajudante de pedreiro. As profissões que podem ser apontadas como aquelas que precisavam de uma determinada especialização para serem desempenhadas, nesse segundo grupo, são: operários, costureiro/costureira, mosaiqueiro, fundidor de granilite, fiador, foguista, marceneiro, carpinteiro, alfaiate, mecânico, ajudante de mecânico, ajudante de ferreiro e instalador de redes, sendo que esse trabalhador instalava redes telefônicas na Companhia Telefônica Riograndense. Enquanto as demais profissões não necessitavam de especialização: servente, ensacador, estivador, carroceiro, carregador, lustrador, trabalhador braçal, lavadora de garrafas e trabalhadora em barraca. ${ }^{36}$

As profissões, apesar de apontar para um número diversificado de ocupações, demonstram a pouca ascensão profissional dos trabalhadores negros de Pelotas. Eles ainda continuavam realizando trabalhos semelhantes àqueles desempenhados

35 GUTIERREZ, Ester. Negros, charqueadas \& olarias. Um estudo sobre o espaço pelotense. Passo Fundo: Editora da UPF, 2011. p. 141.

36 Ester Gutierrez explica como essa profissão era desempenhada: "Os couros eram amplamente polvilhados de sal e dobrados em dois, de maneira que os pelos ficassem para o lado de fora. Eram dispostos uns ao lado dos outros, em camadas de couro alternadas por camadas espessas de sal. Instalavam-se num edifício especial ou barraca, em pilhas muito grandes, retangulares ou quadrangulares, geralmente pouco elevadas, contendo de dez a 15 camadas expostas umas sobre as outras". Ibidem, p. 279. 
pelos seus antepassados, do século XIX. Como aponta Beatriz Loner, além das ocupações nas charqueadas, até a Abolição em 1888,

\begin{abstract}
Também nas demais atividades econômicas, os negros foram encontrados exercendo atividade variada, tanto durante, quanto depois da escravidão. Praticamente não houve profissão manual que não tivesse representantes dessa etnia em seu desempenho, tanto no período imperial quanto na República. Mas havia muitos trabalhadores especializados entre eles, operários artesãos que exerciam suas atividades no meio urbano, como assalariados ou donos de pequenas oficinas. ${ }^{37}$
\end{abstract}

Essa condição parece não ter se alterado, de forma significativa, no momento em que solicitaram suas carteiras profissionais, nos anos 1930/1940. Há uma continuidade das profissões ocupadas pelos trabalhadores negros, fossem aqueles do século $X I X$ fossem aqueles do século $X X$.

Outro dado obtido a partir das fichas contribui para a questão da pouca ascensão social dos trabalhadores negros de Pelotas. Trata-se de alguns trabalhadores que solicitaram carteira, no conjunto de solicitações do estado do Rio Grande do Sul, e que declararam determinadas profissões que necessitam de ensino técnico ou superior para serem executadas e nas quais não há nenhum trabalhador que tenha declarado sua cor como preta. As profissões são: médico, com 35 brancos, advogado, com 23 brancos, dentista, com oito brancos e 408 professores brancos, dois pardos e dois morenos ${ }^{38}$ Esses dados apontam que a questão da pouca ascensão social não estava evidente apenas em Pelotas, mas também nos demais municípios do estado, com trabalhadores que solicitaram carteira profissional. Ainda, de acordo com os dados das fichas, há informações de apenas um bancário e uma enfermeira com registro de cor como preta, sendo que o local do pedido não foi Pelotas.

Outro conjunto de dados relevantes se refere ao grau de instrução. Dos 60 trabalhadores, 39 declararam ter o ensino primário, 13 analfabetos, dois não informaram, outros quatro declaram saber ler, escrever e assinar o nome, enquanto um não sabe ler, escrever e assinar o nome..$^{39}$ Ao somar os analfabetos com aqueles que não informaram e aquele que não sabe ler, escrever e assinar o nome tem-se 16 trabalhadores. Esse dado se torna mais relevante quando cruzado com aquele

37 LONER, op. cit., 1999, p. 2-3.

38 Outras informações sobre os trabalhadores negros no Rio Grande do Sul podem ser acessadas em: LOPES, Aristeu Machado. Os trabalhadores negros a partir das fichas de qualificação profissional da Delegacia Regional do Trabalho do Rio Grande do Sul (1933-1943). In: VI ENCONTRO ESCRAVIDÃO E LIBERDADE NO BRASIL MERIDIONAL - A experiência dos africanos e seus descendentes no Brasil, 2013, Florianópolis/SC. Anais [...]. Florianópolis: UFSC, 2013. p. 1-17. Disponível em: http://www.escravidaoeliberdade.com.br/site/images/Textos.6/aristeuelisandro.pdf. Acesso em: 9 set. 2017.

39 A informação de apenas um trabalhador não foi encontrada. O modelo das primeiras fichas apresenta os campos: sabe ler, sabe escrever, assina o nome. O segundo modelo das fichas altera e simplifica esses campos para apenas "grau de instrução". 
sobre o ano de nascimento: oito trabalhadores analfabetos nasceram no século XIX, de um total de 13 nascidos entre 1882 e 1899. Portanto, a maioria dos alfabetizados com ensino primário nasceu no século $X X$.

O grau de instrução, ao contrário do que foi apontado para as profissões as quais não viabilizam uma ascensão social, indica uma ascensão dos trabalhadores, se comparado com as condições educacionais do século XIX quando o ensino era algo ainda restrito apenas aos filhos dos charqueadores ou às demais famílias com condições financeiras. Por outro lado, é possível apontar que os alfabetizados, sobretudo os nascidos no século XIX, tenham frequentado os cursos noturnos de instrução primária ministrados na Biblioteca Pública Pelotense, entre 1877 e os anos 1950:

Não é demais afirmar que os cursos noturnos da BPP foram uma das experiências mais significativas que Pelotas vivenciou no século XIX em relação à instrução primária das classes populares. Lá, os homens - de qualquer idade - aprendiam a ler, a escrever, a contar, noções de aritmética e de gramática, História e Geografia. ${ }^{40}$

Conforme a autora, os cursos se mantiveram exclusivos para homens até o ano de 1915. Neste ano, "as mulheres conquistaram o direito efetivo de frequentar aulas gratuitas na Biblioteca, para aprender a ler e a escrever, as aulas eram diurnas". ${ }^{41}$ Tal informação se torna relevante para compreender outro dado das fichas desses trabalhadores, no que se refere ao seu grau de instrução e ao sexo. Entre os 60 trabalhadores, há apenas quatro fichas de mulheres. A ficha da trabalhadora mais velha, nascida em 1891, registrou que ela era analfabeta enquanto as outras três - nascidas em 1920, 1922 e 1925, respectivamente, apontaram que todas eram alfabetizadas. É possível considerar que essas três trabalhadoras, ao contrário da primeira, usufruíram de condições educacionais, talvez dos cursos da biblioteca, que possibilitaram que elas estudassem, atingindo o grau primário ou, pelo menos, no caso daquela nascida em 1922, saber ler, escrever e assinar o nome. Por outro lado, a presença de apenas quatro mulheres, nesse universo de 60 trabalhadores, é uma marca da exclusão social e de gênero que as trabalhadoras negras sofriam.

Em relação ao campo sexo, como apontado acima, 56 homens e apenas quatro mulheres. Os dados do banco sobre a presença de mulheres entre as solicitações indicam uma porcentagem de $21,79 \%$, e entre aquelas fichas com o campo cor preenchido como preta, esse número diminui para $0,83 \%$. Novamente é possível

40 PERES, Eliane Teresinha. Relações de gênero, classe social e grupo étnico nos cursos noturnos masculinos de instrução primária da Biblioteca Pública Pelotense (1875-1915). História da Educação, v. 1, n. 1, p. 23, 1997.

41 Ibidem, p. 31. 
retomar a pouca ascensão social e profissional que eram pequenas no universo dos trabalhadores negros e eram ainda menores entre as trabalhadoras negras. Elas continuavam com as profissões exercidas pelas mães, avós e bisavós em tarefas domésticas, como lavadeiras, cozinheiras, passadeiras ou como vendedoras ambulantes, ocupações em que ter uma carteira profissional nem sempre era algo que se enquadrava no perfil dos requerentes de carteira profissional. As quatro trabalhadoras presentes nos dados da DRT/RS desempenhavam as seguintes profissões: a trabalhadora analfabeta era lavadora de garrafas e as alfabetizadas eram magarefe, costureira e trabalhadora em barraca.

Outro dado relevante sobre esses trabalhadores é o estado civil. A maioria era de solteiros: 37 trabalhadores, seguido pelos casados: 20 e viúvos: três. Quase todos os casados declaravam ter dependentes, os quais poderiam ser os pais, esposas ou filhos. Apenas uma, entre as quatro trabalhadoras, era casada e declarava ter cinco filhos dependentes. Um dos trabalhadores declarou ter nove dependentes: a esposa e oito filhos (segundo trabalhador da figura 6). ${ }^{42}$

Entre os solteiros, também se registraram informações sobre dependentes, em especial, o pai e a mãe. No entanto, alguns trabalhadores solteiros, igualmente, apontavam filhos como dependentes e outros declaravam suas companheiras. Fichas de cinco trabalhadores registraram companheiras e, dessas, dois com informações sobre filhos: um trabalhador com um filho e o outro com oito (quinto trabalhador da figura 6). A presença das companheiras nessas fichas demonstra que, apesar do estado civil registrado ser solteiro, esses trabalhadores viviam, de fato, em uma relação afetiva e, provavelmente, dividindo a mesma casa com suas mulheres. Sílvia Arend estudou as relações de amasiamento na Porto Alegre do final do século XIX e apontou três fatores para identificar esse tipo de relacionamento:

As pessoas deviam encontrar-se com alguma regularidade; a existência de responsabilidades mútuas entre o homem e a mulher; e a relação deveria ser pública, ou seja, parentes, vizinhos e amigos e outros tinham conhecimento da sua existência. ${ }^{43}$

A situação dos cinco trabalhadores vai ao encontro desses fatores, uma vez que, ao declarar ter uma companheira como dependente, esses homens reconheciam o seu relacionamento e o explicitavam ao registrá-lo em suas carteiras. Arend complementa: "Para os populares, estar amasiado era considerado um estado próprio da sua cultura, equivalente a um estado civil da ordem jurídica" ${ }^{44}$ No entanto,

42 As fotografias serão analisadas logo na sequência do artigo.

43 AREND, Silvia Maria Fávero. Amasiar ou casar? A família popular no final do século XIX. Porto Alegre: UFRGS, 2001. p. 61.

$44 \quad$ Ibidem, p. 61. 
ainda conforme a autora, para a polícia e a justiça, os amásios eram considerados como solteiros, o que justifica, portanto, o registro do campo estado civil como solteiro nas fichas desses cinco trabalhadores. A condição de amasiado pode ter sido dada pelo próprio trabalhador ou, outra possibilidade, o preenchimento desse campo, com tal informação, foi feito pelo próprio funcionário da DRT/RS encarregado pelo registro dos dados na ficha.

Essas informações, entre outras constantes nas fichas de qualificação profissional, permitem traçar um perfil dos trabalhadores negros de Pelotas a partir da análise dos dados anotados. A ficha, além de possibilitar averiguar os dados pessoais e profissionais dos trabalhadores e trabalhadoras, permite ver os seus rostos registrados nas fotografias $3 \times 4$, item fundamental à solicitação da carteira profissional. Esses registros visuais "faz-nos pensar sobre o passado, a partir do dado de materialidade que persiste na imagem", ${ }^{45}$ ou seja, a materialidade da fotografia permite acessar o passado dos trabalhadores, as formas como eles se apresentaram diante do fotógrafo e as dinâmicas que envolveram a captura dos seus semblantes.

A análise dessas fotografias, em pequeno formato, portanto, configura uma discussão sobre como elas podem ser consideradas não somente um suporte à história dos trabalhadores negros de Pelotas, como também à sua memória. Jacques Le Goff aponta que a fotografia "revoluciona a memória", pois a multiplica e a democratiza permitindo "guardar a memória do tempo e da evolução cronológica". ${ }^{46} \mathrm{~A}$ afirmação do autor é aplicada, sobretudo, em relação àquelas fotografias familiares, as quais registram a memória familiar e acompanham a sua evolução. No entanto, nem sempre a fotografia desempenha apenas a função de registro da memória familiar; sua tarefa, como repositório de memória, pode ser mais ampla. Ela pode ser associada à construção de outros elementos que dão suporte à memória como, por exemplo, as fotografias que serão analisadas neste artigo.

Dito com outras palavras, as fotografias $3 \times 4$ dos trabalhadores negros pelotenses podem ser as únicas referências visuais sobre esses trabalhadores; talvez não haja um suporte familiar, já que uma parte nasceu nas duas últimas décadas do século XIX e o trabalhador mais jovem em 1925. Dessa forma, é possível que os descendentes biológicos, na atualidade, não tenham conservado lembranças de seus antepassados e, assim, a fotografia $3 \times 4$ que restou conservada na ficha do trabalhador seja a única memória fotográfica desses homens e mulheres.

45 MAUAD, Ana Maria. Poses e flagrantes: ensaios sobre história e fotografias. Niterói: UFF, 2008. p. 47.

46 LE GOFF, Jacques. História e memória. Campinas: Editora da UNICAMP, 2003. p. 460. 
Do grupo dos 60 trabalhadores analisados neste artigo, 44 tiveram suas fotografias preservadas no acervo. ${ }^{47} \mathrm{~A}$ figura 1 apresenta um conjunto de fotografias $3 \times 4$ de sete trabalhadores fotografados fora de um estúdio. É possível apontar a hipótese de que eles foram registrados em seus próprios locais de trabalho. Os três primeiros foram fotografados no mesmo ambiente, na rua, e com o aproveitamento da luz natural de um dia ensolarado. O fundo das duas primeiras fotografias revela, de forma mais nítida, o espaço aberto, com árvores, enquanto a terceira foi feita com uma parede servindo como fundo.

\section{Figura 1}

Waldomiro Moraes de Oliveira, oleiro; João Dias Cardoso, oleiro; Antônio Pereira, carroceiro; João Candido, sapateiro; Pedro Marques dos Santos, sapateiro; Arnaldo

Cardoso, ensacador; Pedro Ferreira da Costa, marceneiro.
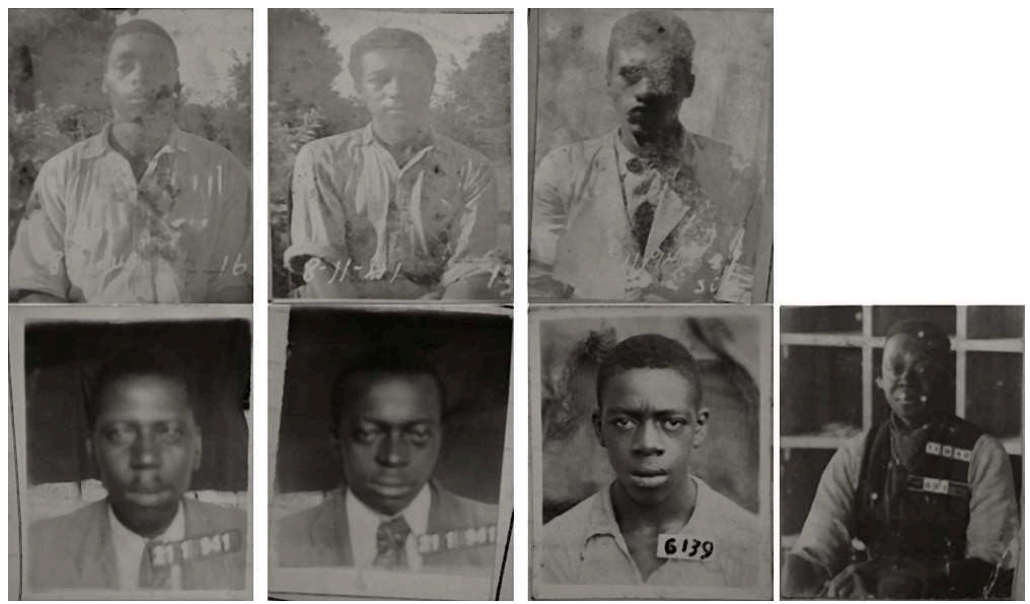

Fonte: Acervo DRT/RS-NDH/UFPel.

Os dois primeiros estão com as mangas das camisas dobradas, um provável indício de um dia de trabalho que foi interrompido para os registros e, após a conclusão, ambos retornaram às suas atividades. As fotografias desses três trabalhadores não cumpriram duas exigências do decreto. Conforme o artigo $6^{\circ}$ :

As fotografias que figurarão na carteira deverão reproduzir a imagem da cabeça tomada de frente, com as dimensões aproximadas de três centímetros por quatro, tendo, num dos ângulos, em algarismos bem visíveis, a data em que tiverem sido feitas, não se admitindo fotografias tiradas mais de um ano antes da sua apresentação. ${ }^{48}$

A primeira não observação ao artigo está no enquadramento, que reproduziu não apenas a cabeça, mas metade do corpo dos trabalhadores. Não se tem

47 As demais fotografias se perderam das suas fichas antes da chegada do acervo no NDH/UFPel. Outras sofreram com o tempo e se apagaram, o que não permite uma reprodução com qualidade.

48 BRASIL. Decreto $n .^{\circ}$ 21.175, de 21 de março de 1932. Institui a carteira profissional. Disponível em:http://www2.camara.leg.br/legin/fed/decret/1930-1939/decreto-21175-21-marco-1932-526745publicacaooriginal-1-pe.html. Acesso em: 21 out. 2017. 
informações sobre implicações técnicas em relação ao enquadramento, se impediria a confecção da carteira. Provavelmente, isso não ocorreu, já que no acervo se encontram muitas fotografias na mesma situação e, por outro lado, o formato da fotografia, o $3 \times 4$, estava correto. A segunda não observação é a data do registro. Nesse caso, a falha do fotógrafo, que não incluiu a placa fixada na roupa dos trabalhadores - como exemplifica as demais fotografias - foi resolvida com a anotação posterior, feita à mão, com uma data. No caso dessas três fotografias, 8 de novembro de 1941.

Os dois primeiros trabalhadores desenvolviam suas atividades em uma olaria, localizada no Quarto Distrito, área rural de Pelotas, e a profissão de ambos era oleiro. É provável que o fotógrafo tenha se deslocado até a área rural para registrar os trabalhadores, já que além deles, há outros 25 trabalhadores fotografados em condições semelhantes, inclusive outros dois oleiros da mesma empresa.

Já foi averiguado que nem sempre os trabalhadores iam até um estúdio fotográfico, mas, acontecia o contrário: o fotógrafo ia até os trabalhadores e improvisava um fundo, geralmente com um tecido escuro, como é o caso da quarta e da quinta fotografia desta mesma figura. ${ }^{49}$ É possível notar que há uma improvisação do fundo, que tenta esconder o que está atrás e dar uniformidade ao registro, como em um estúdio. No entanto, a imagem capturada dos trabalhadores revela o que não deveria aparecer na revelação da fotografia. Ao observar as duas fotografias, é verificado que se trata de caixas de sapatos, o que expõe que seus registros foram feitos no ambiente de trabalho. Os dois trabalhadores tinham sapateiro como profissão e trabalhavam na mesma sapataria. Dessa forma, a fotografia deixa evidente que seus registros, feitos no mesmo dia, foram realizados durante o expediente e no local de trabalho.

Já o sexto trabalhador igualmente teve seu registro com um fundo improvisado. Ao contrário das duas fotografias anteriores, com os fundos compostos por tecidos escuros, esta teve o fundo arrumado com um tecido mais claro e não uniforme. $A$ profissão registrada na ficha era ensacador e era desempenhada em uma fábrica de vidros. Em relação ao sétimo trabalhador, sua fotografia captou mais do que somente o seu rosto, sendo possível ver seus braços, uma de suas mãos e o seu chapéu, enquanto no fundo é possível ver um tipo de prateleira. Esse trabalhador era marceneiro e trabalhava nas obras da reconstrução do Frigorífico Anglo; foi fotografado com vários outros trabalhadores do mesmo frigorífico e em idêntico dia

49 LOPES, Aristeu Machado. As fotografias 3x4 dos trabalhadores do Rio Grande do Sul no acervo da Delegacia Regional do Trabalho, 1933-1943. In: SPERANZA, Clarice Gontarski; SCHEER, Micaele Irene (orgs.). Trabalho, democracia e direitos. V. 2: Mundos do trabalho, identidades e cultura operária Porto Alegre: Editora Fi, 2019. p. 403-422. 
- 11 de setembro de 1942 -, sendo todos os registros feitos fora de um estúdio. ${ }^{50}$

Outra possibilidade para entender o porquê desses registros no ambiente de trabalho está na obrigação da fotografia ser feita antes da solicitação da carteira, ou seja, quando o funcionário da DRT/RS fosse preencher a ficha com os dados dos trabalhadores a fotografia já deveria estar com eles. Dessa forma, era corriqueiro que o fotógrafo se dirigisse até o local de trabalho e realizasse os registros de forma continuada, como fica evidente em várias fichas do acervo. Nesses casos, os documentos são sequenciais pelo número da solicitação e com as fotografias com datas iguais ou em dias aproximados, sendo os trabalhadores do mesmo estabelecimento, na maioria das ocorrências. O caso do trabalhador do Frigorífico Anglo exemplifica essa situação. Parece que o fotógrafo de Pelotas ${ }^{51}$ agiu da mesma forma que o fotógrafo Assis Horta, que produziu os registros em formato $3 \times 4$ de trabalhadores de uma fábrica de tecidos localizada na Vila de Biribiri, em Diamantina, no estado de Minas Gerais, a partir de 1943. Ao chegar na fábrica, Horta "montou ali um estúdio improvisado" 52 e começou a registrar os trabalhadores sempre optando por uma parede ou um tecido escuro para compor o fundo. ${ }^{53}$

A figura 2 apresenta duas dentre as quatro mulheres que solicitaram carteira. ${ }^{54}$ Ambos os registros, ao contrário daqueles da figura 1, foram realizados em estúdio e, provavelmente, pelo mesmo fotógrafo, já que a placa com a data é igual e a moldura é semelhante.

Figura 2

Haydeé da Silva Cruz, trabalhadora em barraca; Arminda Silveira, costureira.
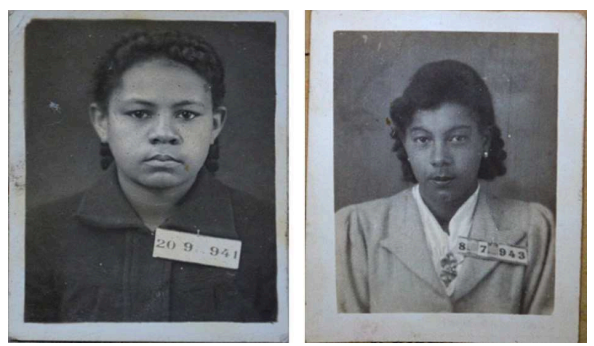

Fonte: Acervo DRT/RS-NDH/UFPel.

50 Sobre as fotografias dos trabalhadores que estavam vinculados às obras do Frigorífico Anglo, ver: LOPES, Aristeu Machado; SCHMIDT, Mônica Renata. Os trabalhadores no Frigorífico Anglo de Pelotas no acervo da Delegacia Regional do Trabalho do Rio Grande do Sul: história, memória e fotografia. Revista Tempos Históricos, v. 22, p. 398-423, 2018.

51 Não foi possível localizar informações suficientes para identificar o fotógrafo, ou os fotógrafos, responsável por todas as fotografias analisadas no artigo.

52 SILVA, Cléber. O olhar de Assis Horta: tradição e dignidade em retratos de operários. 2017. Dissertação (Mestrado em Artes, Cultura e Linguagens) - Universidade Federal de Juiz de Fora, Juiz de Fora, 2017. p. 100.

53 Ibidem, p. 99.

54 Em relação às outras duas trabalhadoras, as fotografias se perderam de suas fichas. 
A ficha da primeira trabalhadora registrou sua profissão como trabalhadora em barraca, em um curtume, enquanto a ficha da outra trabalhadora apontou costureira como profissão. A segunda trabalhadora não tinha vínculo empregatício. A solicitação da carteira por trabalhadores sem vínculos é verificada nos dados do acervo da DRT/RS e inclui uma gama variada de profissões. Possivelmente, essa busca pela carteira se dava para, quando conseguir um emprego, já estar na posse do documento, facilitando a contratação. Essa interpretação pode ser aplicada para o caso das costureiras, no entanto, é possível considerar que ter a carteira era um comprovante da profissão exercida e que elas poderiam buscar emprego para além do trabalho de costura por conta própria.

As próximas figuras $(3,4$ e 5 ) apresentam trabalhadores fotografados em estúdios fotográficos. Todos usam casaco e gravata com variadas estampas.

\section{Figura 3}

Álvaro Ruiz, ajudante de funileiro; Luiz Domingues da Rosa, servente de pedreiro; Maximiano Vergara Junior, curtumeiro; Luiz Silva, operário, Emilio Mendes de Azevedo, alfaiate; Delamar da Gloria Ribeiro, mecânico; João Regis da Silveira, carpinteiro, Izidoro Régis da Silveira, carpinteiro.
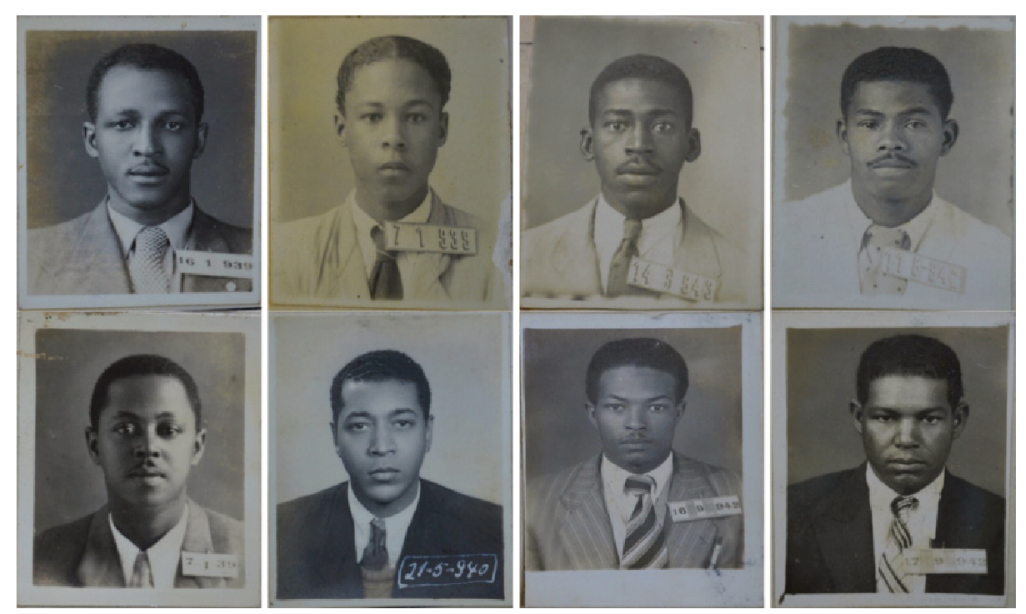

Fonte: Acervo DRT/RS-NDH/UFPel. 


\section{Figura 4}

Dorílio de Deus, curtumeiro; Adão Correa Victoria, magarefe; Waldemar Morales, carpinteiro; Martim José Pinto, pedreiro; Arcelino Correa, ajudante de mecânico; Dionisio Gomes de Oliveira, curtumeiro; Prudêncio Rodrigues, trabalhador braçal; Edmar Fagundes de Oliveira, servente de pedreiro.
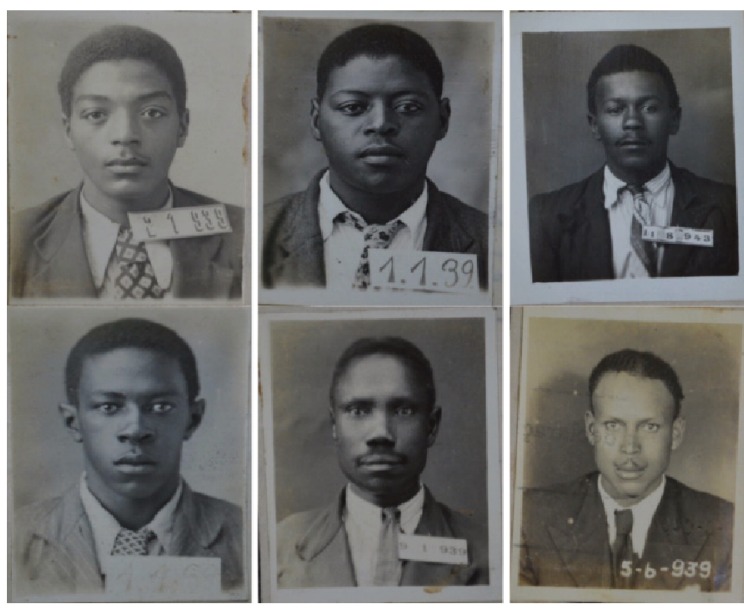

Fonte: Acervo DRT/RS-NDH/UFPel.

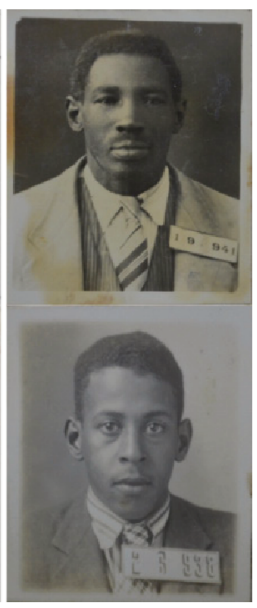

\section{Figura 5}

Lourenço Afonso Lorena, pedreiro; Jeronymo Antunes, operário; Antônio Joaquim Ramos, sapateiro; Carsínio Magalhães, pedreiro; Porfírio Correa, pintor; Geraldo Ávila, lustrador; Eduardo Rosa Rodrigues, ajudante de ferreiro; João Soares Batista, operário.

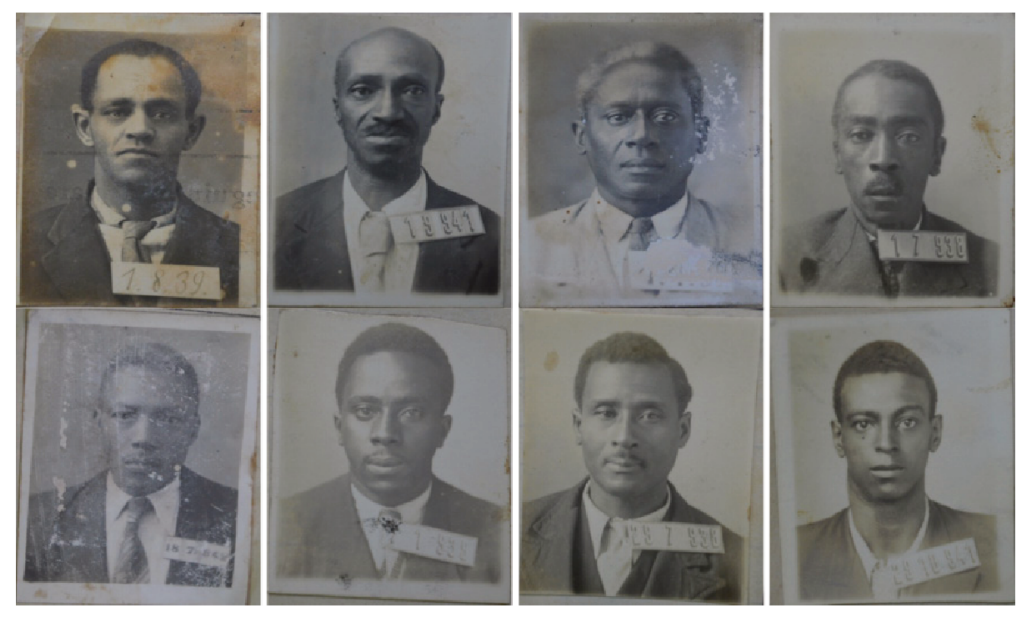

Fonte: Acervo DRT/RS-NDH/UFPel.

Sandra Koutsoukos, ao estudar as fotografias produzidas no século XIX, enfatiza que "o estúdio tornou-se o lugar onde as pessoas podiam explorar (e até brincar com) a sua identidade". ${ }^{55}$ Annateresa Fabris considera que a fotografia oitocentista pode constituir uma identidade retórica ou fictícia:

55 KOUTSOUKOS, Sandra Sofia Machado. Negros no estúdio do fotógrafo. Brasil, segunda metade do século XIX. Campinas: Editora da UNICAMP, 2010. p. 63-64. 
Se a pose responde, num primeiro momento, a imperativos técnicos, assume rapidamente o caráter intrínseco de apresentação de um simulacro. Graças a ela o sujeito torna-se um modelo; deixa-se captar como uma forma entre outras, ao interagir com o cenário que the confere uma identidade retórica quando não fictícia, fruto de uma composição plástica e social a um só tempo. ${ }^{56}$

As reflexões das autoras são adaptadas à análise das fotografias dos trabalhadores que solicitaram carteira profissional, não apenas aos trabalhadores negros, mas a um conjunto maior de fotografias. Em outras palavras, as fotografias $3 \times 4$ permitem compreender como os trabalhadores e trabalhadoras se apresentaram diante do fotógrafo, como constituíram suas formas de apresentação de si e a escolha pelas roupas que usaram para o registro. Dessa forma, os trabalhadores constituíram uma identidade, possivelmente retórica, semelhante ao entendimento de Annateresa Fabris.

As fotografias dos trabalhadores negros que formam os conjuntos das figuras 3, 4 e 5 exemplificam tais considerações, já que todos eles se apresentaram elegantemente trajados no estúdio fotográfico. No entanto, ao comparar as fotografias com as profissões, é possível apontar que muitos deles vestiam suas melhores roupas ou, como afirmou Miriam Leite, seus trajes domingueiros, ou com a roupa de sair de casa, ou de festa, ${ }^{57}$ ou seja, eles apresentaram-se conformando uma identidade retórica, distante daquela identidade forjada pelas suas profissões.

As fichas daqueles da figura 3 registraram as seguintes profissões: ajudante de funileiro, servente de pedreiro, curtumeiro, operário, alfaiate, mecânico, carpinteiro e carpinteiro. ${ }^{58}$ Já os da figura 4: curtumeiro, magarefe, carpinteiro, pedreiro, ajudante de mecânico, curtumeiro, trabalhador braçal e servente de pedreiro. Enquanto aqueles da figura 5: pedreiro, operário, sapateiro, pedreiro, pintor, lustrador, ajudante de ferreiro e operário. Possivelmente o trabalhador alfaiate seja o único que estivesse vestido de acordo com sua profissão, enquanto todos os demais se vestiram com suas melhores roupas, as quais não eram usadas no exercício de suas atividades. Ao comparar esses conjuntos fotográficos com aquele da figura 1 , nota-se que, ao contrário destes, todos os trabalhadores do primeiro conjunto não tiveram a oportunidade para se prepararem para a confecção de suas fotografias, as quais os registraram com suas roupas cotidianas, de trabalho.

56 FABRIS, Annateresa. Identidades virtuais. Uma leitura do retrato fotográfico. Belo Horizonte: Editora da UFMG, 2004. p. 58.

57 LEITE, Miriam Moreira. Retratos de família: Leitura da fotografia histórica. São Paulo: EDUSP, 1993. p. 97.

58 Os dois últimos são irmãos e trabalhavam na mesma empresa. O primeiro porta uma caneta no bolso do casaco. 


\section{ARISTEU ELISANDRO MACHADO LOPES}

As figuras 6 e 7 também apresentam fotografias de trabalhadores realizadas em estúdios fotográficos. Em ambos os conjuntos eles vestem casacos, mas sem gravatas, sendo que alguns deles estão com lenços com cores e nós variados.

\section{Figura 6}

Waldomiro Alves da Silva, sapateiro; Orlando Gonçalves, curtumeiro; Antônio Goularte, sapateiro; Laudelino Dutra, servente; João Francisco da Rosa, servente; Waldemar Oliveira, operário
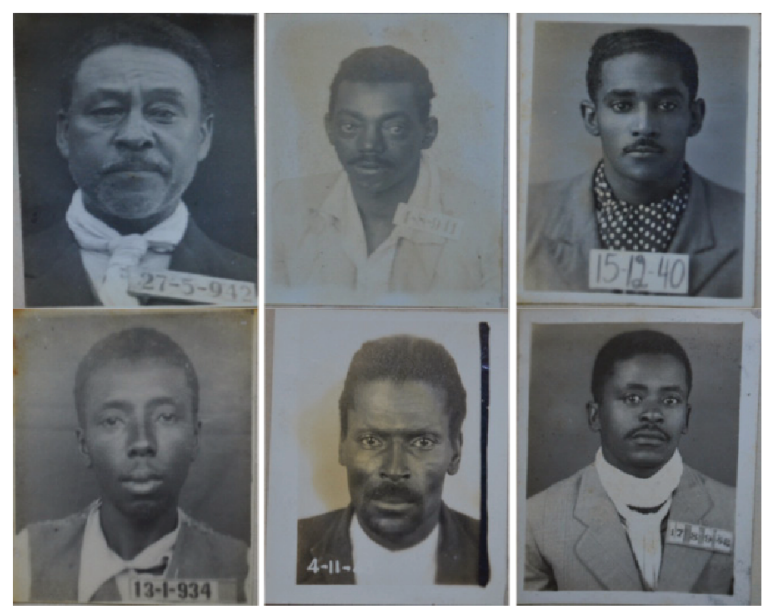

Fonte: Acervo DRT/RS-NDH/UFPel.

\section{Figura 7}

Emílio dos Santos, estivador; Jeremias Braga, ajudante de pedreiro; Domingos Wilson Fernandes, sapateiro; Ildefonso Vergara Cruz, curtumeiro; Francisco Assis da Costa, instalador de redes.

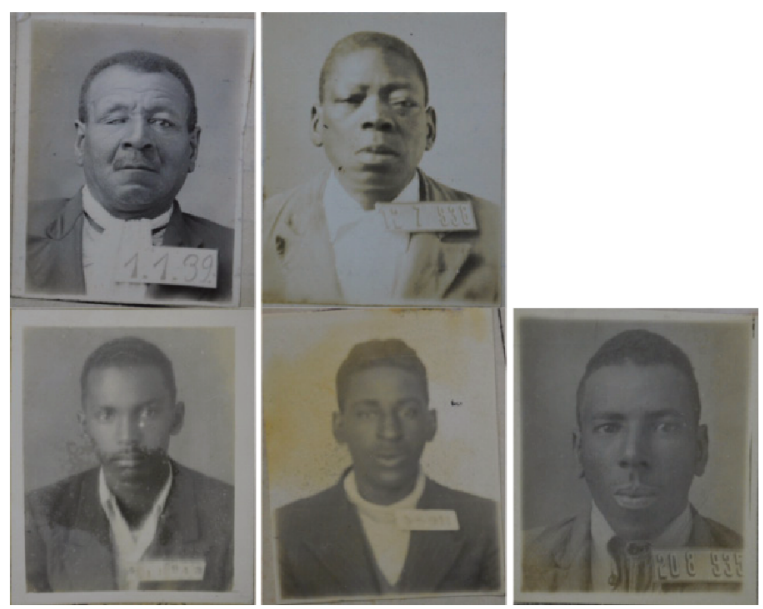

Fonte: Acervo DRT/RS-NDH/UFPel.

O primeiro trabalhador da figura 7 é o mais velho dentre todos os 60 trabalhadores. Nascido em 11 de janeiro de 1882, casado, declarou ter a esposa e dois filhos como dependentes. No momento da solicitação da carteira, 1939, tinha 
57 anos, era estivador e estava desempregado. No campo sinais particulares, sua ficha registrava "falta o olho direito". Apesar da idade, ainda continuava trabalhando e, possivelmente, como era estivador, não possuía vínculo empregatício, já que "o estivador recebe por produção, em cima de taxas nas mercadorias carregadas e organizadas" 59 o que o levou a declarar que estava desempregado, mas, possivelmente, seu trabalho ocorria de acordo com o movimento do porto.

As fotografias dos trabalhadores dos conjuntos que compõem as figuras de 3 a 7 identificam a forma como eles se apresentaram diante do fotógrafo. O cuidado com o vestir-se, o cabelo alinhado, a barba raspada e o bigode aparado demonstram a preocupação em construir uma imagem de si. Iguais observações podem ser feitas para as trabalhadoras da figura 2, as quais também se preocuparam com a construção de suas imagens na hora da produção das fotografias. Esse cuidado, igualmente, pode ser compreendido a partir da importância que era dada para a carteira profissional, um documento que se tornaria um cartão de visitas quando fossem procurar um novo emprego. Por outro lado, a própria fotografia pode ser entendida como um evento social importante. Para muitos desses trabalhadores, com recursos limitados, o ato de tirar uma fotografia não era algo corriqueiro e talvez fosse o caso de alguns deles estarem posando para um fotógrafo pela primeira vez, o que contribui para a compreensão da forma como se apresentaram para o registro.

\section{Considerações finais}

Beatriz Loner aponta que os trabalhadores negros, no período posterior à Abolição, e em especial aqueles de Pelotas e de Rio Grande estudados por ela, tinham "que vencer obstáculos maiores que aqueles colocados aos demais trabalhadores". ${ }^{60}$ Complementa afirmando que: "A situação do negro na República Velha era extremamente débil. Imerso numa sociedade acostumada a tratá-lo como escravo, frágil em seus apoios culturais e econômicos". ${ }^{61}$ A pouca presença de trabalhadores em Pelotas nos dados das fichas da DRT/RS com registro da cor como preta, vai ao encontro dessas considerações.

59 CEDREZ, Thiago. Desautonomização e precarização do trabalho: considerações sobre esse processo com os estivadores do Rio Grande/RS a partir da modernização do porto. In: Marcelo Vianna et al. (org.). O historiador e as novas tecnologias: reunião de artigos do II Encontro de Pesquisas Históricas-PUCRS. Porto Alegre: Ministério Público do Rio Grande do Sul, 2015. p. 1.328.

60 LONER, op. cit., 2016, p. 180.

61 Ibidem, p. 181. A autora demonstra em sua tese como os trabalhadores construíram uma ampla rede de associações, clubes e jornais, entre as quais estavam clubes carnavalescos, sociedades musicais, grêmios dramáticos e os jornais A Alvorada, A Vanguarda e A Cruzada. Essa rede possibilitava a organização e a conscientização da população negra de Pelotas e de Rio Grande, assim como davam respaldo em momentos de crise. Ibidem, p. 167-197. 
As fichas dos 60 trabalhadores foram preenchidas, em sua maioria, em 1939, ou seja, em um período posterior, mas próximo àquele definido por Beatriz Loner em sua tese de doutorado (1888-1937). Em outras palavras, a situação do trabalhador negro, no final dos anos 1930 e começo da década seguinte, na cidade, continuava semelhante àquela verificada no período anterior. Exemplifica essa situação as profissões que eram anotadas nas fichas dos solicitantes de carteira profissional - nascidos e trabalhando em Pelotas -, as quais, em sua maioria, continuavam semelhantes aos trabalhos manuais desempenhados pelos trabalhadores negros desde o século XIX, como pedreiros, sapateiros, curtumeiros, oleiros e marceneiros.

Em outra perspectiva, a pouca presença de fichas de trabalhadores negros aponta para uma conclusão importante: isso não significava que em Pelotas o número de trabalhadores negros fosse pouco representativo, mas, ao contrário, denotava que uma parte considerável dessa mão de obra continuava à margem da legislação trabalhista, desempenhando atividades de trabalho informais ou por conta própria. ${ }^{62}$ A ficha de qualificação profissional, entretanto, é uma forma de dar visibilidade para uma parte da população negra, permitindo a construção de um perfil profissional e trazendo elementos para compreender a sua história.

Em relação à fotografia $3 \times 4$, ela se torna parte importante para compreender a história desses trabalhadores e trabalhadoras. A ficha apresenta os dados pessoais e profissionais do trabalhador, mas é somente a partir do seu registro no formato $3 \times 4$ que é possível verificar como eles se deixaram fotografar. Alguns não tiveram a chance de ter um cuidado com a forma como foram fotografados - como exemplificam aqueles da figura 1 , possivelmente com as fotografias feitas durante o expediente. Outros, ao contrário, tornaram o ato de ir ao estúdio fotográfico um momento importante de suas trajetórias e tiveram um cuidado maior na preparação da imagem de si que fora captada pelo fotógrafo. A fotografia, portanto, é a única parte do documento analisado neste artigo que permite tais considerações, além de dar visibilidade aos semblantes dos homens e mulheres comuns, trabalhadores e trabalhadoras acessíveis no presente, provavelmente, apenas a partir das suas fotografias $3 \times 4$ afixadas nas suas fichas.

Recebido em 05/08/2019

Aprovado em 16/10/2019

62 Importante explicar que o presente artigo não objetivava investigar outras fontes que poderiam trazer informações sobre uma maior quantidade de ocupações dos trabalhadores negros, visto que tal proposta extrapolaria os objetivos do texto que visa apenas os dados da DRT/RS. 